\title{
Nicos Poulantzas e a teoria politica do fascismo: 50 anos depois
}

\author{
Nicos Poulantzas and the political theory
}

of fascism: 50 years later

\section{Danilo Enrico Martuscelli*}

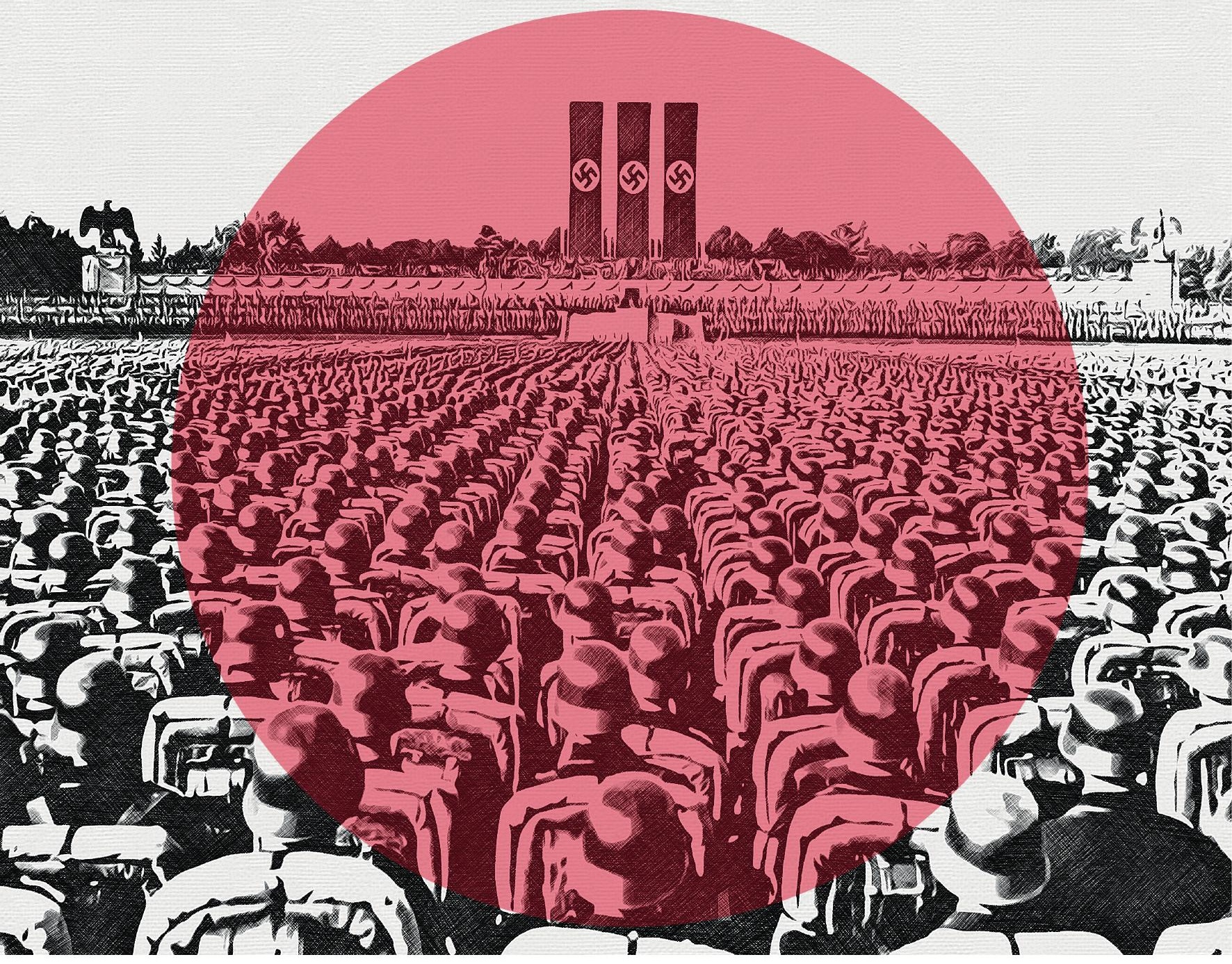




\section{RESUMO}

O objetivo deste artigo é realizar um balanço crítico das teses expostas por Nicos Poulantzas na obra Fascismo e ditadura. Em linhas gerais, o texto propõe-se a discutir os alcances e limites dessa obra enquanto teoria política do fascismo, o que implica levar em consideração os seguintes aspectos: a) a relação entre teoria política e história e sua contribuição para a elaboração de uma periodização política do fascismo; e b) a caracterização do fascismo como forma de regime específica do "Estado capitalista de exceção", ou, como preferimos definir: o fascismo como regime político ditatorial particular inscrito no desenvolvimento histórico da forma de Estado capitalista ditatorial.

Palavras-chave: Nicos Poulantzas. Fascismo. Teoria política.

\section{ABSTRACT}

The aim of this article is to make a critical assessment of the theses exposed by Nicos Poulantzas in the work Fascism and dictatorship. In general, the text proposes to discuss the scope and limits of this work as a political theory of fascism, which implies taking into consideration the following aspects: a) the relationship between political theory and history and its contribution to the elaboration of a political periodization of fascism; and b) the characterization of fascism as a form of specific regime for the "capitalist state of exception", or as we prefer to define: fascism as a particular dictatorial political regime inscribed in the historical development of the form of dictatorial capitalist state.

Keywords: Nicos Poulantzas. Fascism. Political theory. 


\section{INTRODUÇ̃̃o}

Em 2020, a publicação da primeira edição da obra Fascisme et dictature: la III ${ }^{e}$ Internationale face au fascisme (doravante: Fascismo e ditadura), de Nicos Poulantzas, completou 50 anos ${ }^{1}$. Trata-se de um livro teoricamente orientado pelo marxismo e que pode ser caracterizado como uma das obras clássicas sobre o fenômeno do fascismo, por conta de seu rigor analítico, de sua originalidade e de sua repercussão no debate intelectual e político internacional ${ }^{2}$.

Diferentemente dos estudos e discussões pioneiros que abordaram o tema do fascismo no calor dos acontecimentos, Poulantzas empreende uma análise post factum desse fenômeno, ou seja, empreende um estudo com considerável distanciamento histórico em relação às experiências concretas mais emblemáticas do fascismo: a Alemanha de Hitler e a Itália de Mussolini, o que lhe permitiu: a) articular analiticamente as causas, a dinâmica e os resultados do processo de consolidação dessa experiência; b) observar a relação e as defasagens entre as dimensões econômica, ideológica e político-estatal para abordar o processo de crise correspondente a esse fenômeno; c) tratar do papel das classes e frações de classe nesse processo, orientado por uma problemática teórica que analisa as classes sociais em suas dimensões econômica, política e ideológica; e d) debater um conjunto de reflexões produzidas sobre o tema, por intelectuais marxistas e não marxistas, nos 25 anos posteriores à derrota política do fascismo na Segunda Guerra Mundial.

Como a questão do fascismo vem ganhando cada vez mais espaço nos debates públicos atuais com a emergência de movimentos e governos de extrema-direita em várias partes do mundo, como é o caso do governo Bolsonaro no Brasil, torna-se oportuno realizar um balanço crítico das teses expostas por Nicos Poulantzas na obra Fascismo e ditadura ${ }^{3}$. Nesse sentido, propomo-nos a enfatizar neste artigo a discussão sobre os alcances e limites dessa obra enquanto teoria política do fascismo, o que implica levar em consideração os seguintes aspectos: a) a relação entre teoria política e história

1 A primeira versão do livro foi lançada em francês pela editora François Maspero (Paris, França) em 1970. A segunda versão, publicada pelas editoras Seuil e François Maspero em 1974, sofreu algumas mudanças em relação à versão original. Deixaram de figurar nessa nova edição do livro: o subtítulo La IIle Internationale face au fascisme; o anexo "L'URSS et le Komintern"; as análises concretas dos casos alemão e italiano do último capítulo da obra, que abordava a questão do Estado fascista, e os últimos parágrafos das conclusões. Ademais, foram realizados vários ajustes estilísticos na nova publicação do livro. A edição disponível em língua portuguesa foi traduzida por João G. P. Quintela e Maria Fernanda S. Granado, tendo sido publicada pela Portucalense Editora (Porto, Portugal) em dois volumes, em 1972, e reeditada no Brasil com o selo da editora Martins Fontes (São Paulo), em 1978a. Em 2021, uma nova edição dessa obra foi publicada pela editora Enunciado, com tradução de Bethânia Negreiros e revisão do autor deste artigo.

2 Essa obra foi difundida em vários países, tendo sido traduzida para várias línguas, entre as quais mencionamos a alemã, a castelhana, a grega, a inglesa, a italiana, a portuguesa e a turca. No debate sobre as ditaduras latino-americanas nos anos 1970 e início da década de 1980, não foram poucas as referências à análise poulantziana do fascismo. Ver, por exemplo: Cassigoli (1975); Borón (1977); Kelly (1977) e Trindade (1983)

3 Inspirado nos estudos de Poulantzas e de outros intelectuais comunistas como Antonio Gramsci, Palmiro Togliatti e Daniel Guérin sobre o fenômeno do fascismo, Boito Jr. (2020a, 2020b) foi um dos primeiros analistas a formular, de forma consistente, a tese de que Bolsonaro representaria um movimento político e um governo fascistas, ponderando, contudo, que não havia ainda se estabelecido um regime político fascista no Brasil. 
e sua contribuição para a elaboração de uma periodização política do fascismo, e b) a caracterização do fascismo como forma de regime específica do "Estado capitalista de exceção", ou, como preferimos definir: o fascismo como regime político ditatorial particular inscrito no desenvolvimento histórico da forma de Estado capitalista ditatorial.

\section{TEORIA POLITICA E HISTÓRIA: A PERIODIZAÇ̃̃O POLITICA DO FASCISMO}

Um dos principais objetos de análise da obra Fascismo e ditadura são as teses sobre o fascismo aprovadas no âmbito da III Internacional Comunista, entidade criada em I9I9, que congregava organizações e partidos comunistas de várias partes do mundo. É a partir da avaliação crítica dessas teses e de suas variações táticas e estratégicas na conjuntura dos anos I920 e I930 que Poulantzas concluirá que a concepção economicista acerca do fascismo, advogada pela III Internacional, contribuiu para desarmar política e ideologicamente o movimento operário e comunista internacional nessa conjuntura histórica por estar marcada pela "ausência de linha de massa" e pelo "abandono do internacionalismo proletário", elementos considerados relevantes para a eficácia política da luta dos comunistas contra o fascismo.

No entanto, Poulantzas não prioriza em sua análise a discussão sobre a estratégia política e a eficácia de uma dada linha política a ser adotada pelos comunistas contra o fascismo, nem considera que os fatores subjetivos que envolvem a tática e a estratégia políticas dos comunistas por si só explicam as dificuldades da luta antifascista nas décadas de 1920 a I940. Estratégia e eficácia políticas são concebidas mais como resultado do que como ponto de partida de sua caracterização do fascismo. Ao longo de toda a sua obra, ele se dedica a realizar um trabalho de refutação, incorporação e assimilação crítica de uma ampla gama de estudos e reflexões sobre o fascismo, orientados por diferentes problemáticas teóricas e políticas.

Assim, sua contribuição principal para o exame do fascismo irá se constituir no terreno da teoria política, lugar a partir do qual ele mobiliza e articula uma série de noções e conceitos, tais como: forma de Estado, forma de regime, bloco no poder, cena política, ditadura, democracia, classes e frações de classe, fração hegemônica, fração reinante, classe detentora do aparelho de Estado, aparelhos repressivo e ideológicos de Estado, hegemonia e crise de hegemonia etc.. Ele formula, de maneira original, o conceito de fascismo como uma "forma particular de regime da forma de Estado capitalista de exceção”. Portanto, é possível concordar com Jessop (I985) ${ }^{4}$ quando ele afirma que Fascismo e ditadura abriga reflexões sobre estratégia e teoria política, mas consideramos que é a teoria política do fascismo que ocupa o posto de comando nessa obra e orienta o conjunto de suas análises 5 .

4 Jessop (1985) insiste na tese de que Poulantzas não se ajustava muito bem à definição de Perry Anderson acerca do "marxismo ocidental" justamente por conectar em sua obra teoria e estratégia política, ao contrário de outras análises, como as empreendidas pela Escola de Frankfurt, que teriam abandonado a reflexão sobre a estratégia política.

5 Ao fazer um balanço geral sobre a concepção de Estado e revolução no itinerário intelectual de Poulantzas, Codato (2008) defende também que, no conjunto de suas obras principais formuladas a partir de 1968, é possível extrair da caracterização do Estado capitalista uma concepção de estratégia política. 


\section{Em geral, as análises historicistas tendem} a criar uma relação de identidade entre conceito e fato histórico e a considerar que a validade do conceito de fascismo encontra-se associada ao tempo e lugar em que ele foi produzido. É contra tal tendência que Poulantzas se pronuncia no exame do fascismo. Para ele, o fascismo não é um fenômeno datado das décadas de 1920 a 1940 ou geograficamente confinado a duas formações sociais europeias

Para compreender melhor a originalidade do trabalho de Poulantzas, é preciso nos distanciar de algumas possibilidades de interpretação de sua obra que tomam aquilo que é secundário como principal. Nessa perspectiva, consideramos que a obra Fascismo e ditadura não pode ser enquadrada como um trabalho historiográfico. $\mathrm{O}$ próprio Poulantzas já havia nos alertado sobre essa questão. De fato, a obra contém análises concretas sobre os casos dos fascismos alemão e italiano, mas, como o autor observa, tais análises são tomadas fundamentalmente como ilustrações históricas do objeto de investigação:

Não se trata aqui de um estudo historiográfico dos fascismos alemão e italiano, mas de um estudo de teoria política: certamente, este estudo só pode ser feito através de uma pesquisa histórica aprofundada. Mas nem o tratamento do material nem, sobretudo, a ordem de exposição podem ser os mesmos nos dois casos. No caso presente, propusemo-nos a esclarecer os traços essenciais do fascismo como fenômeno político específico: os "acontecimentos" históricos e os detalhes concretos são somente aqui retidos e expostos na medida em que permitem ilustrar com pertinência o objeto da pesquisa (POULANTZAS, 1970, p. 9).

Não está em questão colocar em dúvida a necessidade de aprofundar o debate historiográfico sobre o tema, apontando suas lacunas, limites e alcances, mas, diferentemente da crítica historiográfica realizada por Caplan (1977) à interpretação do fascismo feita por Poulantzas, para os propósitos deste artigo, consideramos mais adequado tratar daquilo que é central em sua obra: a teoria política do fascismo. Com 
isso, torna-se oportuno debater inicialmente dois aspectos centrais de seu livro que estão relacionados à construção de sua teoria política e à história. Referimo-nos à crítica ao historicismo e à periodização política do fascismo.

Em geral, as análises historicistas tendem a criar uma relação de identidade entre conceito e fato histórico e a considerar que a validade do conceito de fascismo encontra-se associada ao tempo e lugar em que ele foi produzido ${ }^{6}$. É contra tal tendência que Poulantzas se pronuncia no exame do fascismo. Para ele, o fascismo não é um fenômeno datado das décadas de 1920 a I 940 ou geograficamente confinado a duas formações sociais europeias. Como uma das formas de regime do "Estado capitalista de exceção", o fascismo apresenta-se como fato histórico que pode se manifestar em contextos históricos distintos do original, como é o caso também do bonapartismo e das ditaduras militares.

Ao parafrasear Horkheimer, para quem aqueles que não falam em capitalismo deveriam se calar sobre o fascismo, Poulantzas (I970, p. I3) sustenta que "quem não quiser falar de imperialismo é que deveria também se calar em relação ao fascismo". Ou, ainda, "o fascismo [...] situa-se no estágio imperialista do capitalismo". Portanto, o fascismo é caracterizado como fenômeno histórico típico do estágio imperialista do capitalismo, mais especialmente de suas conjunturas de crise, não tendo surgido em épocas históricas anteriores. Isso não leva o autor a concluir que toda crise imperialista resultaria necessariamente na emergência do fascismo, uma vez que tal fenômeno manifesta-se concretamente como um dos resultados possíveis - nem único, nem inevitável - do processo de crise do imperialismo. Tal assertiva pode ser válida tanto para entender o próprio contexto do fascismo original ${ }^{7}$ como para compreender as possibilidades de ressurgimento desse fenômeno em conjunturas posteriores, afastando, assim, a análise de Poulantzas de uma visão historicista que confinaria o fascismo em um período histórico particular ${ }^{8}$.

Sobre a periodização política, que só pode ser, de maneira consistente, realizada post factum, Poulantzas retoma as discussões presentes na obra Poder politi-

6 Retomamos aqui as observações críticas feitas por Boito Jr. (s.d.).

7 Sobre o contexto do pós-Primeira Guerra Mundial, Hobsbawm (1995, p. 116-121) observa que as forças de direita foram as únicas responsáveis pela derrubada dos regimes liberal-democráticos e uniam-se em relação aos seguintes pontos: "Todos eram contra a revolução social, e na verdade uma reação contra a subversão da velha ordem social em 1917-20 estava na raiz de todos eles. Todos eram autoritários e hostis às instituições políticas liberais, embora às vezes mais por motivos pragmáticos do que por princípios [...]. Todos tendiam a ser nacionalistas, em parte por causa do ressentimento contra Estados estrangeiros, guerras perdidas ou impérios insuficientes, e em parte porque agitar bandeiras nacionais era um caminho tanto para a legitimidade quanto para a popularidade." No entanto, havia diferenças entre essas forças que podem ser observadas nos contrastes de três tipos distintos: 1) "Autoritários ou conservadores anacrônicos [..., [que] não tinham qualquer programa ideológico particular, além do anticomunismo e dos preconceitos tradicionais de sua classe"; 2) o "'estatismo orgânico' [...] ou regimes conservadores, não tanto defendendo a ordem tradicional, mas deliberadamente recriando seus princípios como uma forma de resistir ao individualismo liberal e à ameaça do trabalhismo e do socialismo", que visavam substituir a democracia liberal pela "representação de grupos de interesse econômico e ocupacional"; e 3) os movimentos fascistas, que eram "os revolucionários da contrarrevolução", "denunciavam a emancipação liberal" e "desconfiavam da corrosiva influência da cultura moderna", descrita como "'bolchevismo cultural' e degenerada".

8 Voltaremos à discussão sobre a relação entre fascismo e imperialismo mais adiante. 
co e classes sociais, publicada em $1968^{9}$, em especial as relacionadas à teoria do bloco no poder, para aplicá-las à análise política do fascismo ${ }^{\mathrm{IO}}$. Isso pode ser observado no modo como mobiliza os conceitos de fração hegemônica, cujos interesses preponderam diante da política de Estado sobre os das demais frações que integram o bloco no poder; de fração reinante, cujos interesses reinam no âmbito da cena política ou terreno dos partidos e que exerce o domínio ideológico sobre o conjunto das classes sociais, e de classe detentora do aparelho de Estado, classe que ocupa o alto escalão do Estado. Além disso, a periodização política do processo de fascistização proposta por Poulantzas leva em consideração as viragens que ocorrem nesses três níveis em decorrência das lutas entre classes e frações de classe.

$\mathrm{Na}$ análise de Poulantzas, os casos concretos dos fascismos alemão e italiano são vinculados ao processo de transição do capitalismo concorrencial ao capitalismo monopolista, mas, como ele salienta: "o fascismo não é, de modo algum, um fenômeno exclusivamente ligado a esse "período", pois corresponde ao fenômeno geral das crises políticas, resultantes das lutas de classe numa dada conjuntura e que "podem muito bem surgir em períodos diferentes" (POULANTZAS, I970, p. 53-54).

Para esses mesmos casos concretos, o autor observa certa dinâmica política que se processa por meio das seguintes etapas:

a) um dos fatores principais que cria condições para a emergência do processo de fascistização é a derrota estratégica da classe operária e das massas populares após confrontação com as classes dominantes em um processo de ofensiva política, como foram os casos das experiências revolucionárias que malograram na Alemanha, em I9I8-ı9I9, e na Itália, em I9I9-I920;

b) o que se observa, na sequência, é um processo em que a burguesia se coloca na ofensiva política e que corresponde a um "processo de politização declarada da luta de classes por parte do bloco no poder" (POULANTZAS, I970, p. 72), mas tal ofensiva ocorre em um contexto de crise de hegemonia que afeta a organização do bloco no poder e permite a emergência de uma força social (a pequena burguesia) que se apresenta na cena política de forma organizada num partido de massas: o partido fascista;

c) tal situação perdura até o "ponto de não retorno" ou de "irreversibilidade", que se caracteriza como tal por coincidir com a concretização da aliança entre a

9 Recentemente, essa obra foi republicada e recebeu uma nova tradução no Brasil. Ver: Poulantzas (2019a).

10 Bensaïd (1973) afirma que Fascismo e ditadura deve ser entendida como obra na qual Poulantzas aplica à análise concreta os conceitos produzidos em Poder político e classes sociais. Essa tese só é verossímil se considerarmos os conceitos e noções que se articulam em torno de sua teoria do bloco no poder. $O$ mesmo não se pode dizer de sua caracterização do Estado capitalista como estrutura jurídico-política, formada pelo direito burguês e pelo burocratismo, que marca efetivamente a relação de Poulantzas com as teses expostas por Althusser e seu grupo nas obras Pour Marx e Lire Le Capital, publicadas em 1965. Tais teses, ligadas à matriz oficial althusseriana e que estão na base do conceito de Estado capitalista formulado em Poder político e classes sociais, foram abandonadas por Poulantzas em Fascismo e ditadura, que passou a adotar o conceito de Estado capitalista como sendo constituído por um conjunto de aparelhos (repressivo e ideológicos). Para uma crítica do conceito de Estado capitalista desenvolvido em Fascismo e ditadura, ver: Martuscelli (s.d.). 
pequena burguesia, organizada no partido fascista, e o grande capital monopolista, que confisca a revolta pequeno-burguesa e passa a dirigi-la politicamente, garantindo assim as condições para a chegada do fascismo ao poder;

d) no primeiro período do fascismo no poder, a pequena burguesia se estabelece como classe reinante, por conta dos fortes vínculos dessa fração com o partido fascista e da presença maciça desse partido na cena política, e começa a se tornar classe detentora do aparelho de Estado, ao se colocar nos principais postos do alto escalão do Estado. Já o grande capital monopolista projeta-se como fração hegemônica do bloco no poder, pois o Estado fascista passa a cumprir a função de priorizar os interesses materiais daquela fração, colocando fim à crise de hegemonia, assim como de neutralizar as contradições entre a nova fração hegemônica e as demais frações dominantes;

e) na última etapa, que corresponde à estabilização do fascismo no poder, o grande capital monopolista se estabelece como fração hegemônica e desloca a pequena burguesia da condição de fração reinante na cena política, na medida em que a capacidade governativa real é transferida para a polícia política e em que ocorre a subordinação do partido fascista à burocracia de Estado.

Ainda que se tenha de ponderar que a periodização política proposta por Poulantzas toma como referência o fascismo original constituído como forma de regime, chama-nos a atenção o modo sofisticado como ele aborda o processo político, suas distintas dimensões, e as conecta com as lutas travadas entre classes e frações de classe. Dessa periodização política, é possível extrair algumas conclusões que podem orientar a análise da ascensão e consolidação do fascismo em diferentes épocas históricas.

A primeira delas é a de que a ascensão política do fascismo é precedida por um processo de derrota estratégica do movimento operário e popular. Ou seja, a ascensão do movimento fascista está ligada a uma situação em que o movimento operário e popular se encontra na defensiva depois de ter passado por sucessivas derrotas políticas. Tal tese dista de uma série de análises que procuraram identificar a emergência do fascismo como resposta à ofensiva do movimento socialista, como se estivesse na ordem do dia a disjuntiva socialismo ou fascismo.

A segunda delas é a de que o fascismo emerge em uma conjuntura de crise política, ou melhor, de crise de hegemonia, resultante de um acúmulo de contradições, que tem impacto sobre o âmbito da organização do poder político — isto é, nenhuma das frações dominantes consegue impor direção política ao bloco no poder, provocando a oscilação de uma situação de instabilidade para outra de incapacidade hegemônica - e sobre a cena política, observada pela crise de representação política que afeta a relação entre as frações da classe dominante e suas organizações e partidos tradicionais, que passam para a coxia da cena política, para utilizarmos uma metáfora teatral. Nessa etapa, o conjunto do bloco no poder coloca-se na ofensiva política contra os trabalhadores: "a luta política do bloco no poder contra as massas populares detém o papel dominante em relação à luta econômica” (POULANTZAS, I970, p. 72). Novamente, Poulantzas analisa o fascismo em toda a sua complexidade, 
Poulantzas analisa o

fascismo em toda a sua

complexidade, distanciando-

se de interpretações sobre

esse fenômeno que tendiam

(e tendem) a ocultar ou

secundarizar as diferenças

entre democracia liberal e

fascismo ao concebê-los como

Edição brasileira de

Fascismo e Ditadura:

A III Internacional face

ao fascismo (Enunciado

Publicações, 2021)

regimes representativos do

grande capital

distanciando-se de interpretações sobre esse fenômeno que tendiam (e tendem) a ocultar ou secundarizar as diferenças entre democracia liberal e fascismo ao concebê-los como regimes representativos do grande capital.

A terceira conclusão que podemos tirar dessa análise é a de que a combinação de derrota estratégica das classes populares, crise de hegemonia política no seio do bloco no poder e crise de representação política das classes dominantes (crise dos partidos tradicionais) abre espaço para a constituição da pequena burguesia como força social organizada na forma de partido de massas. A pequena burguesia, que ocupa uma posição intermediária entre as duas classes sociais fundamentais, se torna a base social ou força motriz principal do movimento fascista.

A quarta conclusão é a de que a aliança da pequena burguesia com a fração dominante que se pretende alçar à condição de fração hegemônica no bloco no poder é fundamental para consolidar o fascismo no poder. Isso quer dizer que a base social do fascismo, oriunda principalmente da massa da pequena burguesia, passa a ser dirigida politicamente pelos interesses do grande capital monopolista, que orienta a revolta pequeno-burguesa para os seus propósitos políticos, e isso permite ao fascismo se estabelecer no poder. $\mathrm{Ou}$, para sermos mais precisos, a chegada do fascismo ao poder está ligada a um processo de redefinição da hegemonia política no seio do bloco no poder e de ruptura institucional que se concretiza com a constituição de um novo ramo do aparelho de Estado como ramo dominante em termos de capacidade governativa: o ramo da polícia política. 
A quinta conclusão é a de que o fascismo se constitui em um regime político ditatorial que conta com uma base social de massa organizada e mobilizada, que se diferencia tanto do caráter predominantemente tecnocrático das ditaduras militares - que evitam a politização das massas e tendem a contar, no máximo, com apoio maciço esporádico (ou ocasional) no processo de implementação do novo regime quanto das ditaduras bonapartistas que possuem base social de massas, mas esse apoio se concretiza passivamente, sem se converter em uma força social organizada e mobilizada na cena política, ou seja, as ditaduras bonapartistas não abrangem a existência de um partido que organize sua base social de apoio. Essas conclusões sobre a comparação das bases sociais das ditaduras fascista, bonapartista e militar não são sistematizadas por Poulantzas na obra Fascismo e ditadura. ${ }^{\text {II }} \mathrm{O}$ autor apenas aborda a existência do partido fascista de massas como um aspecto definidor do fascismo. Contudo, consideramos fazer esses acréscimos, já que diferenças entre esses três tipos de ditadura não se limitam à configuração de um ramo específico do aparelho estatal como ramo dominante, segundo sugere Poulantzas: a polícia política, no fascismo, a burocracia civil, no bonapartismo, e as Forças Armadas, na ditadura militar. Consideramos que as distintas configurações das bases sociais de apoio nos três casos - bases sociais organizadas e mobilizadas no fascismo, base que oferece apoio passivo no bonapartismo e apoio esporádico (ou ocasional) na ditadura militar — são também aspectos importantes para definir tais regimes.

Por fim, a sexta conclusão é a de que as funções de fração hegemônica (quem exerce o poder político?, ou quem tem seus interesses priorizados pelo conteúdo da política estatal?), reinante (quem exerce o domínio ideológico na cena política?, ou, no caso específico do fascismo, quem é a força motriz do movimento de massas?) e detentora do aparelho de Estado (quem governa?, ou, ainda, qual é o pertencimento de classe de quem executa a política estatal?) sofrem transformações ao longo de todo o processo de fascistização e consolidação do fascismo, vindo a ser ocupadas por diferentes classes e frações de classe.

Diante do exposto, consideramos que esse instrumental teórico manejado

11 Poulantzas desenvolve a discussão sobre o fenômeno do bonapartismo na "Parte IV - A unidade do poder e a autonomia relativa do Estado capitalista" da obra Poder político e classes sociais. Aqui se inserem tanto o debate sobre o problema da autonomia relativa do Estado capitalista, quanto a caracterização do bonapartismo como forma política particular situada nos limites do Estado capitalista. Em uma das notas de rodapé dessa obra, Poulantzas (2019a, p. 303-304) aponta para a necessidade de estabelecer uma distinção entre o Estado bonapartista e o Estado fascista, e crítica a posição de Thalheimer de diluir os dois conceitos em um só. Já a referência à ditadura militar aparece, de modo mais sistematizado, em A crise das ditaduras, obra na qual Poulantzas (1975) trata das contradições de classe que foram fundamentais para a emergência de uma crise política específica que resultou na queda das ditaduras militares de Portugal, Grécia e Espanha. Em seu último livro, Poulantzas (1978b, p. 231-232) dedica uma reflexão ao fenômeno do "estatismo autoritário" que, na visão dele, "não é nem a forma nova de um Estado de exceção, nem, em si, a forma transitória para tal Estado: ele representa a nova forma democrática da república na fase atual". A elaboração deste conceito permite ao autor colocar em evidência os limites da forma de Estado democrático que emerge no contexto histórico de crise do Estado de bem-estar social e de ascensão do capitalismo neoliberal em âmbito global, fase histórica que é marcada: a) pelo reforço político do Executivo sobre os processos decisórios fundamentais; b) pelo declínio do Parlamento; c) pela crise dos partidos políticos e d) pela exclusão acentuada das massas populares dos centros de decisão política. 
por Poulantzas para analisar o processo de fascistização e de consolidação do fascismo pode ser concebido como uma ferramenta importante para examinar os zigue-zagues conjunturais típicos de uma crise política, os lugares que as diferentes classes e frações de classe ocupam no processo político e os impactos que os conflitos de classe produzem sobre a organização dos ramos do aparelho de Estado, o conteúdo da política estatal e a cena política. Em resumo, no tocante à periodização política, o estudo realizado por Poulantzas oferece elementos para tratar o fenômeno do fascismo a partir de uma perspectiva que não descura das relações entre classes e instituições estatais/políticas, entre Estado e economia, entre economia, política e ideologia, nem ignora as diferenças entre as classes e frações de classe que exercem o poder político (fração hegemônica), constituem a base social do fascismo (fração reinante) e executam a política estatal (classe detentora do aparelho de Estado) ${ }^{12}$.

Enfatizamos ainda que a análise de Poulantzas não se limita a situar o fascismo em uma fase específica do capitalismo (por exemplo, na transição ao capitalismo monopolista), nem a caracterizar o fascismo como um fenômeno típico das formações sociais capitalistas imperialistas. Para ele, o fascismo é um fenômeno político possível nos marcos do tipo de Estado capitalista da etapa imperialista do capitalismo. O enfoque de Poulantzas também não vincula o fascismo a um tipo específico de política econômica e social (keynesiana, desenvolvimentista, neoliberal etc.) ou a uma configuração interna específica do bloco no poder. Esse conjunto de elementos não é concebido por Poulantzas como aspecto fundamental para a caracterização do fascismo. Dito isso, vale a pena responder à pergunta: o que é o fascismo para Poulantzas?

\section{O FASCISMO COMO "FORMA DE REGIME DO ESTADO CAPITALISTA DE EXCEÇÃO"}

A caracterização do fascismo como "forma de regime do Estado capitalista de exceção" é o aspecto original central da análise desenvolvida em Fascismo e ditadu$\mathrm{ra}^{13}$. Nessa obra, Poulantzas não se dedica ao estudo dos tipos de Estado em geral ou do tipo de Estado capitalista em particular, mas enfoca a discussão sobre a variação das formas de Estado das quais se reveste o tipo de Estado capitalista em sua evolu-

12 Extraímos essas conclusões sobre as bases sociais das ditaduras fascistas, bonapartistas e militares da instigante discussão teórica sobre o conceito de fascismo realizada pelo professor Armando Boito Jr. em um seminário organizado pelo Centro de Estudos Marxistas (Cemarx), da Unicamp, no início de outubro de 2020

13 Outra questão que mostra originalidade e relevância é a relação que o autor procura estabelecer entre - fascismo e as diferentes classes e frações de classe (classes dominantes, classe operária, pequena burguesia e classes sociais no campo). Em particular, Poulantzas realiza uma análise minuciosa das causas da adesão ou não dessas diferentes classes e frações de classe ao fascismo. Esse debate é retomado pelo próprio Poulantzas (2019b) em um artigo publicado em 1975. Infelizmente, em razão da falta de espaço, não teremos condições de tratar desse assunto no presente trabalho. Basta salientar, contudo, que a análise de Poulantzas sobre a relação entre fascismo e classes sociais é muito mais sofisticada e complexa do que aquelas inspiradas pela teoria das elites, que se centram na noção de homem médio ou comum para definir a base social fascista e ocultam, assim, os fatores econômicos, políticos e ideológicos característicos de cada classe e fração de classe que explicam sua adesão efetiva ou potencial ao fascismo. No fundo, a noção de homem médio se constitui em um obstáculo epistemológico para o exame das bases sociais do fascismo, pois se funda, sobretudo, na ideia abstrata acerca da irracionalidade das massas fascistas. 
ção histórica. Em particular, aborda a forma de Estado capitalista de exceção e suas respectivas formas de regime, o que o leva a dar atenção especial ao exame do regime fascista.

Nesse sentido, é possível dizer que Poulantzas refere-se ao conceito de forma de Estado para tratar de duas dimensões analíticas distintas. Numa primeira definição, a forma de Estado alude aos estágios históricos de desenvolvimento capitalista: o capitalismo concorrencial, que corresponde à existência da forma de Estado liberal, e o capitalismo monopolista (imperialismo), que emerge graças à presença da forma de Estado intervencionista.

Para o autor, a forma de Estado intervencionista cumpre um papel importante no processo de transição do capitalismo concorrencial ao capitalismo monopolista, estágio este que é marcado economicamente pela concentração e centralização de capitais, pela emergência do capital financeiro, resultante da fusão dos capitais bancário e industrial, pelo predomínio da exportação de capital sobre o comércio de mercadorias, pela busca incessante de colônias por parte dos países imperialistas em função de razões fundamentalmente econômicas etc. Num plano geral, os traços comuns de todas as experiências que se enquadram na forma de Estado intervencionista seriam os seguintes: "um recrudescimento do papel dos aparelhos ideológicos e uma retração da autonomia relativa desses aparelhos, devido à dominação política massiva do capital monopolista" (POULANTZAS, I970, p. 348). Nesse processo de transição ao capitalismo monopolista, Poulantzas compreende que há, portanto, um reforço do papel do Estado, que, após a Segunda Guerra Mundial, atenua-se.

Nessa primeira definição, a forma de Estado é caracterizada pela relação estabelecida entre o econômico e o político, isto é, a forma de Estado intervencionista diz respeito, como o próprio nome sugere, ao papel intervencionista do Estado na economia com vistas a garantir os interesses do grande capital monopolista. Nos casos alemão e italiano, Poulantzas considera que o reforço do papel intervencionista do Estado pode ser observado em um processo de crescente centralização política que corresponde a uma "unidade nacional vacilante": "poderia dizer-se que, de alguma forma, tudo se passa como se a Alemanha e a Itália tivessem saltado por cima do estágio do Estado liberal" (POULANTZAS, I970, p. 32).

Em linhas gerais, Poulantzas identifica dois modos de manifestação dessa forma de Estado intervencionista: um modo que corresponde à existência de uma estabilidade política, na qual não se observa a ocorrência de uma crise de hegemonia, o que ele chama de forma "normal" de Estado capitalista; e outro que se configura em meio a um processo de crise de hegemonia, o que o leva a caracterizá-lo como forma de Estado capitalista "de exceção". Essa forma de Estado abrigaria três formas de regime: a fascista, a bonapartista e a ditatorial militar.

É justamente a forma de Estado capitalista “de exceção" que ganhará centralidade na análise desenvolvida em Fascismo e ditadura. Ao longo do livro, ainda que pontualmente e em passagens isoladas, o autor faz uso de outras nomenclaturas 
para caracterizá-la, tais como "forma crítica do Estado" (POULANTZAS, I970, p. 326) ou "forma de crise [...] do Estado capitalista" (p. 344). Nota-se, portanto, que tal forma de Estado vincula-se à existência de uma crise política, não revolucionária, que, no caso do fascismo original, apresenta três características fundamentais já referidas acima: derrota estratégica e defensiva do movimento operário e popular, crise de hegemonia política no seio do bloco no poder e constituição da pequena burguesia como força social (partido fascista). Aqui, a caracterização da forma de Estado faz referência à autonomia relativa do Estado em relação ao bloco no poder e ao grande capital monopolista, cuja hegemonia política essa forma de Estado procura estabelecer.

Assim, se os conceitos de forma de Estado capitalista "liberal" ou "intervencionista" aludem à relação entre o político e o econômico, os conceitos de forma de Estado capitalista "normal" ou "de exceção" referem-se à relação entre Estado e classes dominantes. Como a forma de Estado capitalista "de exceção" abrange uma situação histórica de crise de hegemonia, o mais apropriado seria tratá-la como "forma de crise" do Estado capitalista, em vez de empregar a ideia de "exceção" para caracterizá-la, mas o limite dessa definição residiria no fato de que a consolidação do fascismo corresponde ao estabelecimento da hegemonia política do grande capital monopolista e, portanto, à superação da situação de crise de hegemonia. Ou seja, a noção de forma de crise corresponderia mais ao processo de fascistização do que à consolidação do fascismo, ao fascismo estabelecido, constituindo-se como uma noção apenas parcialmente válida e adequada.

A crítica elaborada por Boukalas (2018) à noção de "Estado de exceção" formulada pelo filósofo Giorgio Agamben ajuda-nos a problematizar a categoria exceção concebida como algo em oposição à norma ou distinto dela, tal como empregada por Poulantzas: "Sem conteúdo, a norma é corolário implícito da exceção. Mas a exceção deveria estabelecer seu conteúdo de sua relação com a norma. Se a norma estiver vazia, então vazia é a exceção. Como saber qual é qual?" (BOUKALAS, 20I8, p. 37). Para os propósitos deste artigo, caberia indagar: como é possível descrever uma determinada forma de Estado capitalista como sendo excepcional, se Poulantzas não define ou descreve rigorosamente o que constitui a normalidade? Como já assinalou Boito Jr. (s.d.), nem a tipicidade da democracia burguesa nem a excepcionalidade da ditadura são caracterizadas por Poulantzas, argumento que só reforça a pertinência da analogia que fizemos da crítica de Boukalas a Agamben.

Para tratar da especificidade do que Poulantzas chama de forma de Estado capitalista "de exceção", torna-se oportuno não apenas remeter à ideia de crise política correspondente a tal forma de Estado, como é mais adequado substituir o termo de exceção por ditatorial. Tal operação analítica poderia ser feita retomando as características do Estado capitalista, formuladas em Poder político e classes sociais. Assim, seria necessário observar que, no tipo de Estado capitalista, os membros de todas as classes sociais são concebidos como indivíduos-cidadãos no âmbito do direito civil. Se o tipo de Estado capitalista estabelece essa condição básica que o distingue de outros tipos 
de Estado (escravista ou feudal) que conferem no plano do direito civil um tratamento desigual aos desiguais socioeconomicamente, é possível distinguir duas formas principais de Estado capitalista: a democrática e a ditatorial. Na forma de Estado capitalista democrática: a cidadania política é garantida aos membros de todas as classes sociais; já na forma de Estado capitalista ditatorial, a "cidadania política é negada aos membros de todas as classes sociais" (SAES, I987, p. 52).

Nessa perspectiva, na forma de Estado capitalista democrática, a dissimulação dos interesses de classe que o Estado representa é produzida pela ideologia do povo-nação e garantida pela burocracia estatal (civil e militar) autonomeada e pelos membros dos ramos Executivo e Legislativo, indicados por todas as classes sociais por meio do sufrágio universal. Nessas condições, os membros representantes do povo-nação autonomeados e eleitos passam a deter capacidade governativa real, ou seja, a eles cabe a responsabilidade de implementar a política de Estado, responsabilidade que pode ser compartilhada de maneira hierarquizada ou equilibrada entre o ramo Executivo e o Legislativo. Já na forma de Estado capitalista ditatorial, é a burocracia estatal autonomeada que detém exclusivamente tal capacidade governativa, o que implica conferir ao sufrágio universal um papel nulo ou significativamente secundário a ponto de o Parlamento assumir apenas um papel "decorativo" ou de "pura fachada" em relação às ações da burocracia estatal (SAES, 1987).

Portanto, a característica comum a todas as formas de Estado capitalista ditatoriais, que Poulantzas denomina "de exceção", está ligada ao fato de a burocracia estatal apoderar-se com exclusividade da capacidade decisória antes atribuída constitucionalmente também aos órgãos estatais constituídos por meio de sufrágio universal. Poulantzas apresenta algumas características gerais do que chama de forma de Estado capitalista de exceção, que traduzem bem o que vimos afirmando até aqui. Em relação ao direito, "é o arbitrário que reina" (POULANTZAS, I970, p. 352). Com isso, o Estado passa a contar com certa "liberdade de ação" para reorganizar as relações de forças. Não há limites "juridicamente fixados": "tudo cai virtualmente na esfera da intervenção estatal” (p. 353). Além disso, ocorre a "suspensão do princípio eleitoral”, resultante da crise ideológica e da crise de representação política pela qual passam os partidos burgueses tradicionais. Isso permite acentuar a burocratização e os mecanismos de cooptação e controle da designação dos membros da burocracia estatal, o que não impede o uso de expedientes como plebiscitos ou referendos para legitimar as ações dessa burocracia.

Feitas essas observações sobre o que preferimos chamar de forma de Estado capitalista ditatorial, passemos ao tratamento do fascismo como forma de regime específica e possível dessa forma de Estado. Como já mencionado, Poulantzas trabalha com a tese de que a forma de Estado capitalista "de exceção" admite três formas principais de regime para as quais ele também emprega o qualificativo "de exceção": a ditadura fascista, a ditadura bonapartista e a ditadura militar. Em sua análise, tais formas de regime "não são fenômenos limitados no tempo" 
(POULANTZAS, I972, p. 6) $)^{14}$, podendo ressurgir em outros contextos históricos ainda que não possuindo as mesmas características das formas originais:

Quanto ao próprio fascismo, cujo ressurgimento permanece possível, não deveríamos mais acreditar que ele assumiria inevitavelmente formas idênticas às do passado, nem que o processo de fascistização conduziria às mesmas formas. A história nunca se repete do mesmo modo. Uma mesma forma de regime de exceção e uma mesma espécie de crise política apresentam traços distintos, segundo os períodos históricos no seio dos quais elas surgem (POULANTZAS, I970, p. 393).

O ponto comum a essas três formas de regime é o apoderamento exclusivo da capacidade governativa real por parte da burocracia estatal, o que Poulantzas (I970, p. 358) identifica como “'burocratização' pronunciada”. O aspecto fundamental para distingui-las é aquilo que o autor chama de "ramo dominante do aparelho de Estado". Para ele, a diferença entre as três formas de regime situa-se em termos de predomínio da burocracia civil (ditadura bonapartista), do Exército (ditadura militar) ou da polícia política (fascismo) sobre os demais ramos do aparelho de Estado, ou seja, as formas de regime de "exceção" (que chamamos de ditatoriais) correspondem cada uma a um diferente arranjo das relações estabelecidas entre os ramos do aparelho de Estado. Pelo fato de a instauração dessas formas de regime implicar efetivamente uma ruptura institucional com a forma de regime democrática, nos marcos do tipo de Estado capitalista, uma nova hierarquia entre os ramos do aparelho de Estado se estabelecerá, expressando, assim, um processo de emergência de uma nova fração hegemônica no bloco no poder.

Nesse sentido, Poulantzas estabelece uma relação de correspondência entre ruptura institucional, nova hierarquia dos ramos do aparelho de Estado e redefinição da hegemonia política no bloco no poder. Ainda que tais formas de regime não possam ser definidas por uma caracterização particular do bloco no poder e da fração hegemônica, é possível dizer que os processos de instauração desses regimes estão associados a uma crise política (crise de hegemonia) - processo de fascistização - e a uma redefinição dessa hegemonia - consolidação do fascismo no poder. No caso específico do fascismo, é preciso acrescentar a existência de uma base social de massa organizada e mobilizada que se constitui em fração autônoma na cena política e apoia o regime fascista, o que a distingue das bases sociais típicas da ditadura bonapartista (apoio passivo) e da ditadura militar (apoio esporádico ou ocasional).

Poulantzas também distingue a primeira fase do regime fascista da fase do regime estabelecido. Afirma, assim, que são forças exógenas aos aparelhos de Estado que passam a dominar os ramos desse aparelho, exercendo simultaneamente as funções repressiva e ideológica. Na primeira fase do regime fascista, é o partido fascista que assume esse papel dominante e "invade 'de fora" o aparelho repressivo

14 Fazemos referência aqui à "Nota à edição portuguesa". 
(POULANTZAS, 1970, p. 364). O diferencial da forma de regime fascista em relação às outras formas de regime ditatoriais é justamente a mobilização permanente das massas populares que o partido fascista procura fomentar primeiramente por fora e depois por dentro dos aparelhos de Estado. Ainda que haja contradições entre o partido fascista e os ramos do aparelho de Estado, seu acesso ao poder se dá também por conivência de tais ramos em um primeiro momento, e, posteriormente, com o regime estabelecido, o partido fascista passa a se subordinar ao aparelho de Estado, sem que chegue a se fundir com ele.

Para Poulantzas, a ideologia fascista que orienta a ação do partido fascista como partido de massas atende, em um processo de "adaptação-torção da ideologia burguesa", às aspirações da pequena burguesia. Ainda que tais aspirações contenham aspectos genericamente anticapitalistas de crítica à "grande riqueza", aos monopólios, aos bancos e ao capital de empréstimo, ao analisar a ideologia fascista, o autor destaca uma série de características que podem ser concebidas como sintoma da presença do princípio do burocratismo sob a forma de ideologia do povo-nação. Mais bem dizendo: a ideologia fascista, distante de contradizer o efeito de representação da unidade produzido pelo princípio do burocratismo típico do Estado capitalista, apresenta-se como uma de suas formas possíveis de manifestação, especialmente se considerarmos parte dos aspectos destacados por Poulantzas que constituem essa ideologia, tais como: a estatolatria ou "culto ao Estado", que corresponde ao "fetichismo do poder" sustentado pela pequena burguesia, expressando-se também por meio do "culto ao chefe" e pela defesa de uma "autoridade hierárquica"; o "culto do 'arbitrário", que concebe os regramentos jurídicos como ordem do chefe, o que permite colocar em evidência a "ideologia moral" que se ancora nas noções de "honra e dever"; o elitismo e o racismo antissemita; o nacionalismo, que está associado ao "culto exacerbado da entidade mística que é a "nação'"; o militarismo, que combina nacionalismo, autoritarismo, hierarquia e culto do chefe; e o corporativismo, que se caracteriza como uma forma de assegurar a participação política da pequena burguesia no processo político por intermédio do Estado.

Nessa perspectiva, a ideologia fascista pode ser tratada simultaneamente como expressão das aspirações da pequena burguesia, daí advindo uma das explicações possíveis sobre o caráter de massa do movimento fascista, e como forma de manifestação específica da ideologia do povo-nação. Não é casual, assim, que o partido fascista logre, em um primeiro momento, se acomodar ao aparelho de Estado, na medida em que se desenvolve o processo de fascistização do assim chamado aparelho repressivo. Com o estabelecimento do fascismo, esse mesmo partido fascista passará a se posicionar de maneira subordinada no aparelho de Estado e a atender aos interesses da nova fração hegemônica do bloco no poder: o grande capital monopolista. Com a consolidação do regime fascista, é a polícia política que se torna o ramo dominante e passa a deter o controle sobre o processo decisório estatal. O que caracteriza essa polícia política? 
No caso alemão, o fascismo exerce inicialmente influência sobre a base do Exército e sobre as polícias dos governos locais, o que Ihe permite contornar o controle que a cúpula do Exército realiza de maneira centralizada sobre o aparelho repressivo

A polícia política define-se como o ramo dominante do aparelho de Estado, mas está submetida diretamente à vontade do chefe supremo. Assume progressivamente um domínio ilimitado de intervenção sobre os ramos principais do aparelho de Estado e o conteúdo da política estatal, traduzido no controle de atividades de segurança, de administração e militares. Passa, assim, a deter um papel simultaneamente repressivo e ideológico. Esse processo se consolida por meio daquilo que Poulantzas chama de "conivências profundas" entre o partido fascista e o aparelho policial, tendo como razão explicativa a luta travada pelo aparelho repressivo de Estado contra as massas populares. Sobre essa questão da conivência, é preciso observar que, distante de perder o monopólio do exercício da força e da violência legítima, o aparelho repressivo exercerá um papel importante diante das milícias privadas, ao armá-las: "trata-se aqui, então, de uma transferência ou de uma delegação de funções, recoberta aliás de legitimidade por intermédio da magistratura" (POULANTZAS, I970, p. 367).

Além disso, Poulantzas (1970) atenta para o fato de que o fascismo, enquanto movimento inicialmente exógeno ao aparelho de Estado, procura se infiltrar fundamentalmente através da administração civil e da polícia, realizando o que o autor chama de assalto simultâneo na periferia e no centro desse aparelho. Ou seja, no caso alemão, o fascismo exerce inicialmente influência sobre a base do Exército e sobre as polícias dos governos locais, o que lhe permite contornar o controle que a cúpula do Exército realiza de maneira centralizada sobre o aparelho repressivo. Aos poucos, a própria cúpula do Exército recruta milícias privadas para assegurar a defesa das fronteiras. Assim, as forças milicianas privadas que se encontravam fora do aparelho repressivo passam a se infiltrar nele, constituindo, inclusive, uma "rede paralela de poder", como foi o caso da SS:

O aparelho SS incarna concretamente, para o nacional-socialismo, o deslocamento entre aparelho repressivo de Estado e aparelhos ideológicos de Estado [...; precisamente por causa desse recrutamento massivo e dessa formação ideológica, a polícia política SS não se torna, como é o caso da polí- 
cia secreta em outras formas, um "Estado no Estado" no sentido forte: ela permanece estreitamente controlada pelos dirigentes nacional-socialistas (POULANTZAS, 1970, p. 375).

No caso italiano, as milícias fascistas não cumprem o mesmo papel repressivo e ideológico das milícias SS hitlerianas, exercendo menor influência sobre o aparelho repressivo, uma vez que a própria cúpula do Exército foi conquistada pelo fascismo. Em relação à administração civil, a polícia política exerce o controle sobre as intervenções do aparelho de Estado, mas não sobre seu conteúdo. Em suma, a rede paralela de poder é menos desenvolvida do que a existente na Alemanha, mas, mesmo assim, a polícia política assume o papel dominante sobre o conjunto dos ramos e aparelhos de Estado.

\section{A ATUALIDADE DE FASCISMO E DITADURA: 50 ANOS DEPOIS}

Qual seria a atualidade da obra Fascismo e ditadura, 50 anos depois? Inicialmente, é preciso salientar a caracterização do fascismo como fenômeno histórico que emerge numa situação de crise política particular no seio do desenvolvimento histórico do tipo de Estado capitalista. Como fenômeno histórico, o fascismo não é concebido como algo datado, mas como uma das formas de regime possíveis que o Estado capitalista pode assumir, ou seja, o fascismo é uma possibilidade histórica para a realidade do Estado capitalista. Tal crise política não se confunde, portanto, com uma crise revolucionária, na qual poderia se configurar uma situação de duplo poder que colocaria em xeque a própria existência do Estado capitalista. Trata-se de uma crise política aguda inscrita na própria dinâmica de reprodução do capitalismo, acarretando a ocorrência de complexos e conflituosos processos de realinhamento político de classe. Poulantzas caracteriza essa crise como crise de hegemonia e a vincula à derrota estratégica prévia do movimento operário e popular, à politização da luta do bloco no poder contra as massas populares, à incapacidade de uma fração das classes dominantes para dar direção política a esse bloco no poder, à existência de uma crise de representação política que atravessa os partidos tradicionais e à emergência da pequena burguesia como força social organizada num partido político de massas (o partido fascista).

A resolução dessa crise de hegemonia está diretamente relacionada com os seguintes processos: constituição da aliança da pequena burguesia com o grande capital monopolista, o que Poulantzas aborda como "ponto de não retorno" da ascensão política do fascismo; redefinição da hegemonia política do bloco no poder, que, com o regime fascista estabelecido, é assegurada pelo grande capital monopolista no contexto das experiências clássicas do fascismo; transformações no domínio ideológico, o que permite que o grande capital monopolista exerça a função de fração reinante antes ocupada pela pequena burguesia - esse processo ocorre quando o partido fascista se integra e passa a se subordinar ao aparelho de Estado; configuração da peque- 
na burguesia como classe detentora do aparelho de Estado, o que a torna responsável pela execução da política de Estado do novo regime fascista, e as modificações nas relações dos ramos do aparelho de Estado, abrindo possibilidade para a constituição da polícia política como ramo dominante.

Em termos de teoria política do fascismo, a principal contribuição dada por Fascismo e ditadura foi a de caracterizar o fascismo como uma forma de regime da forma de Estado capitalista de exceção, que preferimos definir neste artigo como forma de Estado capitalista ditatorial. Ademais, a partir de sua análise, é possível identificar dois traços fundamentais que caracterizaram a particularidade da ditadura fascista: um traço institucional, isto é, a polícia política como ramo dominante do aparelho de Estado, e um traço social, a saber, a constituição de um regime político que conta com uma base de apoio organizada e mobilizada. Essas especificidades — institucional e social - marcam a caracterização da ditadura fascista quando, como vimos ao longo do texto, se estabelece uma comparação entre tal ditadura e as ditaduras bonapartista e militar. O exame da especificidade da ditadura fascista, longe de ser mero gozo intelectual ou implicância lexical, tem profundas consequências para a luta antifascista. Não levar em consideração essa especificidade pode resultar em erros táticos e estratégicos de grande magnitude, que inclusive foram cometidos pelo movimento comunista internacional no passado. Como nos lembra Poulantzas (I970, p. 394) nas conclusões de seu livro, "se a história tem um sentido, é o de poder servir de lição para o presente".

* Professor de Ciência Política da Universidade Federal da Fronteira Sul (UFFS) e editor do blog marxismo21. E-mail: daniloenrico@gmail.com A maior parte das ideias desenvolvidas neste artigo foi resultante das discussões feitas durante o minicurso "Nicos Poulantzas e a análise sobre o fascismo", que ministramos conjuntamente com o professor Sávio Cavalcante, da Universidade Estadual de Campinas (Unicamp), no final de novembro de 2019 no Instituto de Filosofia e Ciências Humanas (IFCH-Unicamp). Esse mesmo minicurso foi transformado num conjunto de seminários que realizamos junto com o Grupo de Pesquisa Estado, Direito e Capitalismo Dependente, coordenado pelo professor Adriano Nascimento, do Programa de Pós-Graduação em Serviço Social da Universidade Federal de Alagoas (PPGSS-UFAL), no segundo semestre de 2020. Agradecemos a todos os colegas e todas as colegas com quem pudemos debater a análise poulantziana do fascismo, assim como aos leitores e leitoras de primeira hora deste artigo: André Flores Penha Vale, Angela Lazagna, Caio Navarro de Toledo, Davisson de Souza, Francisco Farias, Francisco Prandi, Paula Marcelino, Santiane Arias e Sávio Cavalcante.

Texto recebido em janeiro de 2021; aprovado em janeiro de 2021 
ALTHUSSER, Louis. Pour Marx. Paris: La Découverte, 2005.

et al. Lire Le Capital. Paris: François Maspero, 1965. 2 t.

BENSAÏD, Daniel. À propos de "Fascisme et dictature": Poulantzas, la politique de l'ambigüité. Critiques de I'Économie Politique, n. 11-12, p. 267-281, 1973.

BOITO JR., Armando. Por que caracterizar o bolsonarismo como neofascismo. Crítica Marxista, $\mathrm{n}$. 50, p. 111-119, 2020a.

Dilma, Temer e Bolsonaro: crise, ruptura e tendências na política brasileira. Goiânia: Editora Philos Academy, 2020b.

Apresentação e discussão do conceito poulantziano de fascismo. In: LAZAGNA, Angela e BERRINGER, Tatiana (Org.). A atualidade da teoria política de Nicos Poulantzas. Santo André: Ed. UFABC, [s.d.]. No prelo.

BORÓN, Atilio. El fascismo como categoría histórica: en torno al problema de las dictaduras en América Latina. Revista Mexicana de Sociología, v. 39, n. 2, p. 481-528, 1977.

BOUKALAS, Christos. Sem exceções: estatismo autoritário - Agamben, Poulantzas e segurança interna. Crítica Marxista, n. 47, p. 27-53, 2018.

CAPLAN, Jane. Theories of fascism: Nicos Poulantzas as historian. History Workshop, n. 3, p. 83-100, 1977.

CASSIGOLI, Armando. Fascismo y fascismo dependiente. Estudios Políticos, v. 1, n. 1, p. 95-127, 1975.

CODATO, Adriano. Poulantzas, o Estado e a revolução. Crítica Marxista, n. 27, p. 65-85, 2008.

HOBSBAWM, Eric. A queda do liberalismo. In: A era dos extremos: o breve século XX (1914-1991). 2. ed. São Paulo: Companhia das Letras, 1995.

JESSOP, Bob. Nicos Poulantzas: Marxist theory and political strategy. London: Macmillan, 1985.

KELLY, Maria Patricia Fernandez. Dos Santos and Poulantzas on fascism, imperialism and the State. Insurgent Sociologist, v. 7, n. 2, p. 23-34, 1977.

MARTUSCELLI, Danilo Enrico. Nicos Poulantzas e o conceito de Estado capitalista na obra Fascismo e ditadura, [s.d.]. Mimeografado.

POULANTZAS, Nicos. Fascisme et dictature: La IIIe Internationale face au fascisme. Paris: François Maspero, 1970.

Fascismo e ditadura: a III Internacional face ao fascismo. Porto: Portucalense, 1972. 2 v.

Fascisme et dictature. Paris: Seuil; François Maspero, 1974.

La crise des dictatures: Portugal, Grèce, Espagne. Paris: François Maspero, 1975.

Fascismo e ditadura: a III Internacional face ao fascismo. São Paulo: Martins Fontes, 1978a.

L'État, le pouvoir, le socialisme. Paris: Presses Universitaires de France, 1978b.

Poder político e classes sociais. Campinas: Editora da Unicamp, 2019a.

Sobre o impacto popular do fascismo. Cadernos Cemarx, n. 12, p. 173-188, 2019b.

SAES, Décio. Democracia. São Paulo: Ática, 1987.

TRINDADE, Hélgio. La cuestión del fascismo en América Latina. Desarrollo Económico, v. 23, n. 91 , p. 429-447, 1983. 